\title{
Optimal Placement and Sizing of Capacitor and Distributed Generation with Harmonic and Resonance Considerations Using Discrete Particle Swarm Optimization
}

\author{
M. Heydari \\ E-mail: hatebird85@gmail.com
}

S.M. Hoss eini

Faculty of electrical engineering, Babol University, Iran E-mail:mehdi.hosseini@nit.ac.ir

S.A. Gholamian

Faculty of electrical engineering, Babol University, Iran E-mail:gholamian@nit.ac.ir

\begin{abstract}
Presence of distributed generation (DG) in distribution systems has significant impacts on the operational characteristics of these systems, also using capacitor for reactive compensation and loss reduction is so common. Injected harmonic currents from nonlinear loads into distribution system distort all of voltages and currents and must be considered when placing the capacitor banks so that the resonance will not occur. In this paper discrete particle swarm optimization (DPSO) approach is used for the optimal placement and sizing of distributed generations and capacitors in distribution systems for simultaneous voltage profile improvement, loss and total harmonic distortion (THD) reduction. There is a term in the objective function which prevents harmonic resonance between capacitor reactance and system reactance. Constraints include voltage limit, voltage THD, number/ size of capacitors and generators. For evaluating the proposed algorith $\mathrm{m}$, the IEEE 33-bus test systemis modified and employed.
\end{abstract}

Index Terms - Capacitor, Distributed Generation, Optimal Placement, Harmonic, Resonance, Discrete Particle Swarm Optimization

\section{Introduction}

Centralized Power plants deliver the electricity to the end-user via transmission system. Distribution system makes a link between the high voltage transmission system and consumers. In distribution system, the voltage levels are low but current levels are high in the compare of transmission system, so the loss, in distribution system is greater than in transmission system. Most of loads connected to distribution systems are induction loads which make the system power factor will be lag and the voltage drop to a lower level even lower than the acceptable range. Any components connected to power system for working properly and safely must receive voltage in the defined range, any voltage out of this boundary can damage these components. In power system, operator is obligated to maintain voltage level of each costumer bus within the required limit. A most acceptable voltage variation is within the range of ${ }_{-5}^{+} \%$ [1].

As mentioned above, drop of voltage is unavoidable, so this drop should be compensating somehow. One of the most widely method is using shunt capacitors. In addition imp roving voltage profile, shunt capacitors can reduce loss, enhance power factor and voltage stability of the system [2]. Another method is using distributed generation (DG).DG is playing an increasing role in distribution system. Improving voltage profile, reducing system losses, reinforcing grid and improving system reliability are some advantages of using DG[3]. All of these advantages will be achieved only on the condition, these (DG \& capacitor) placed in proper buses. Any improper placing may adverse system condition. There have been some studies for optimal placing such as: tabu search [4], analytical approaches [5, 6], secondorder algorithm [7], meta-heuristic approaches [8,4],fuzzy-GA algorithm[10],etc. Most of these techniques suffer from the inability to escape local optimal and burden heavy computational time.Pso(particle swarm optimization) is a good method which is fast and have ability to escape local optimal.Pso is a self-adaptive search optimization was introduced by Kennedy and Ebhart[11]. Pso has been 
applied to many optimization problems such as: dynamic systems [12], optimal capacitor placement in distribution system [13], constrained optimization [14], multi-objective optimization problems [15], etc. Some works have used pso for optimal placing of capacitors, it was considered as a continuous problem but as we know capacitors are commercially available in discrete sizes, so in this paper a modified version of pso which is suitable for discrete problems and is called discrete particle swarm optimization (DPSO) or binary partic le swarm optimization is used .Most of these works consider all of loads are linear and exclude the effect of harmonic in the objective function. But in practice, a portion of loads are none linear because of wide speared use of electronic devices, so it can lead to improper placing because of probation of resonance at some harmonic frequencies. In this paper, there is a term in the objective function which prevents harmonic resonance.

The rest of this paper is organized as follows: in section 2 modeling of network components at harmonic frequencies is discussed. Problem formulation for the objective function for improving voltage profile and minimization of loss and THD is presented in section3.In section 4 the pso algorithm is described briefly. The results of DG and capacitor placement on 33-bus test system are presented and discussed in section5. Finally, section 6 summarizes the main points and results of this paper.

\section{Model of Network Components at Harmonic Frequencies}

In this paper for modeling of network components at harmonic frequencies, some practical and approximation of references $[16,17]$ is used.

\subsection{Cable}

For very accurate model of cable at high frequency some modifications need to be applied to the resistance and inductance of cable. But for practical harmonic analysis a simple model is enough. For the $h^{\text {th }}$ harmonic order the line impedance can be written as:

$$
\mathrm{Z}_{\mathrm{L}}^{(\mathrm{h})}=\mathrm{R}_{\mathrm{L}}+\mathrm{jh} \mathrm{X}_{\mathrm{L}}
$$

\subsection{Transformer}

Because of non-linear magnetizing properties of transformer it is difficult to model it at harmonic frequencies and because of core saturation it produces harmonic itself. For harmonic study in this paper we assume transformer operates in normal condition. So the impedance of transformer at harmonic frequency can be written as:

$$
\mathrm{Z}_{\mathrm{T}}^{(\mathrm{h})}=\mathrm{R}_{\mathrm{T}}+\mathrm{jhX} \mathrm{X}_{\mathrm{T}}
$$

\subsection{Capacitor and Inductor:}

Capacitor and inductor can be modeled similarly and their impedance at harmonic frequency can be expressed by:

$$
\begin{gathered}
X_{C}^{h}=1 / 2 \pi h f c \\
X_{L}^{h}=2 \pi h f L
\end{gathered}
$$

where $f$ is the main frequency of the system.

\section{Problem Formulation}

In this paper the following as sumptions are made:

Capacitors are fixed type.

Both linear and non-linear loads are presented in a balanced 3-phase system.

\subsection{Constraints}

Voltage constraint will be defined as follows:

$$
V^{\min } \leq \sqrt{\Sigma_{h}\left(V_{i}^{h}\right)^{2}} \leq V^{\max }
$$

where $\mathrm{V}^{\mathrm{min}}$ is lower, $\mathrm{V}^{\max }$ is upper bounds of $\mathrm{rms}$ voltage and $V_{i}^{h}$ is $h^{\text {th }}$ harmonic order of voltage at bus $i$. In this paper $\mathrm{V}^{\mathrm{min}}=0.95$ and $\mathrm{V}^{\max }=1.05$.

\section{THD:}

Total harmonic distortion of voltage (THD) should be less than the maximum of allowable

$$
\begin{aligned}
T H D_{v, i} & =\left(\left[\sqrt{\sum_{h \neq 1}^{\left(V_{i}^{h}\right)^{2}}}\right] / V_{V_{i}^{1}}\right. \\
& \leq T H D_{v}^{\max }
\end{aligned}
$$

In this paper according to IEEE-519, $\mathrm{THD}_{\mathrm{v}}^{\max }=0.05$.

\subsection{Indexing}

For forming of objective function some indexes are defined.

\subsubsection{Voltage deviation index}

This index is for improving of voltage profile and defined as follows: 


$$
V D-I=\sum_{i=1}^{n}\left(\frac{V_{n o m}-V_{i}}{V_{n o m}}\right)^{2}
$$

Where $V_{\text {nom }}$ is the nominal of system voltage $\left(V_{\text {nom }}=1\right), V_{i}$ is the voltage at node $i$ and $n$ is number of busses.

\subsubsection{Active and reactive power loss index (PL-I, QL-I)}

$$
\begin{gathered}
P L-I=\frac{P_{L}}{P_{L-N O}} \\
Q L-I=\frac{Q_{L}}{Q_{L-N O}}
\end{gathered}
$$

Where $\mathrm{P}_{\mathrm{L}}, \mathrm{Q}_{\mathrm{L}}$ are active and reactive power losses after installation of DG and capacitor respectively and $\mathrm{P}_{\mathrm{L}-\mathrm{NO}}, \mathrm{Q}_{\mathrm{L}-\mathrm{NO}}$ are active and reactive power loss before installation.

\subsubsection{THD index}

This index is for minimizing of total harmonic distortion:

$$
\mathrm{THD}-\mathrm{I}=\sum_{\mathrm{i}=1}^{\mathrm{n}} \max \left(0,\left(\mathrm{THD}_{\mathrm{i}}-\mathrm{THD}_{\max }\right)\right)
$$

Where $\mathrm{THD}_{\mathrm{i}}$ is the total harmonic distortion of bus $\mathrm{i}$.

\subsubsection{Resonance index (RES-I)}

Many works concerning capacitor placement, consider all loads are linear, recently some works take non-linear loads into account, so the capacitor placement problem mixed with harmonic consideration, but as it is shown in [18] even in these works, capacitor placement led to harmonic resonance at one or some harmonic frequencies. In this paper there is a term in the objective function which prevents harmonic resonance. So resonance index is defined as follow:

$$
\begin{aligned}
\text { RES }-\mathrm{I}= & \sum_{\mathrm{i}=1}^{\mathrm{n}} \sum_{\mathrm{h}=1}^{\mathrm{m}}\left(\mathrm{V}_{\mathrm{i}}^{\mathrm{h}} / \mathrm{V}_{\mathrm{i}}^{\mathrm{h}-\mathrm{no}}\right) \\
& +\sum_{\mathrm{i}=1}^{\mathrm{n}} \sum_{\mathrm{h}=1}^{\mathrm{m}}\left(\mathrm{I}_{\mathrm{i}}^{\mathrm{h}} / \mathrm{I}_{\mathrm{i}}^{\mathrm{h}-\mathrm{no}}\right)
\end{aligned}
$$

Where $V_{i}^{h}, I_{i}^{h}$ are the voltage and current of bus I at $\mathrm{h}^{\text {th }}$ harmonic order after installation and $\mathrm{V}_{\mathrm{i}}^{\mathrm{h}-\mathrm{no}}, \mathrm{I}_{\mathrm{i}}^{\mathrm{h}-\text { no }}$ are before installation of DG and capacitor. When resonance occurs, voltage or current at resonance frequency will increase and may go much more than the nominal amplitude of main frequency. So if resonance occurs, the amplitude of this term will increase and capacitors which make resonance will be omitted automatically in the minimization progress of the algorithm.

\subsection{Objective Function}

By introducing above indexes objective function is defined as follows:

$$
\begin{gathered}
\mathrm{F}=\alpha_{1} \mathrm{VD}-\mathrm{I}+\alpha_{2} \mathrm{PL}-\mathrm{I}+\alpha_{3} \mathrm{QL}-\mathrm{I} \\
+\alpha_{4} \mathrm{THD}-\mathrm{I}+\alpha_{5} \mathrm{RES}-\mathrm{I}
\end{gathered}
$$

where $\alpha$ is the index weight, these weights indicate the importance of each index in the placement problem. They depend on the required analysis.

$$
\sum_{\alpha=1}^{5} \alpha=1 \quad, \quad \alpha \in\left[\begin{array}{ll}
0 & 1
\end{array}\right]
$$

In table 1 these weights is defined, for selecting these weights, the guides of $[19,20]$ is used.

Table 1: index weights

\begin{tabular}{|c|c|c|}
\hline index & Index weight & value \\
\hline$V D-I$ & $\alpha_{1}$ & 0.3 \\
\hline$P L-I$ & $\alpha_{2}$ & 0.2 \\
\hline$Q L-I$ & $\alpha_{3}$ & 0.2 \\
\hline$T H D-I$ & $\alpha_{4}$ & 0.15 \\
\hline$R E S-I$ & $\alpha_{5}$ & 0.15 \\
\hline
\end{tabular}

\section{PSO Algorithm}

Particle swarm optimization is an algorithm developed by Kennedy and Ebhart. This algorithm is based on social behaviors of bird flocking or fish schooling and the methods which they use to find food sources. In a simple way this algorithm is defined as follows:

The search space is d-dimensional

Particle: Each member is called particle and is presented by d-dimensional vector and described as:

$$
X_{i}=\left[x_{i 1}, x_{i 2}, \ldots, \ldots \ldots, x_{i d}\right]
$$

Where $\mathrm{X}_{\mathrm{i}}$ is the (I-th) particle.

Population: a set of $\mathrm{n}$ particles in the swarm is called population and described as:

pop $=\left[\mathrm{X}_{1}, \mathrm{X}_{2}, \ldots \ldots, \mathrm{X}_{\mathrm{n}}\right]$

pbest: the best previous position for each particle is called particle best (pbest) and described as: 


$$
\text { pbest }_{\mathrm{i}}=\left[\mathrm{pb}_{\mathrm{i} 1}, \mathrm{pb}_{\mathrm{i} 2}, \ldots \ldots, \mathrm{pb}_{\mathrm{id}}\right]
$$

gbest: the best position among all of particle is called global best (gbest) and described as:

$$
\text { gbest }=\left[\mathrm{gb}_{1}, \mathrm{gb}_{2}, \ldots \ldots, \mathrm{gb}_{\mathrm{d}}\right]
$$

velocity: the rate of position change for each particle is called particle velocity and described as:

$$
V_{i}=\left[v_{i 1}, v_{i 2}, \ldots \ldots, v_{i d}\right]
$$

updating velocity: at iteration $\mathrm{k}$ the velocity for $\mathrm{d}$ dimension of i-particle is updated by:

$$
\begin{aligned}
V_{i d}^{k+1}= & w v_{i d}^{k}+c_{1} r_{1}\left(p d_{i d}^{k}-x_{i d}^{k}\right) \\
& +c_{2} r_{2}\left(g b_{d}^{k}-x_{i d}^{k}\right)
\end{aligned}
$$

Where $\mathrm{w}$ is the inertia weight, $\mathrm{c}_{1}$ and $\mathrm{c}_{2}$ are the acceleration constants, and $r_{1}, r_{2}$ are two random values in range [0,1]. The acceleration constants $\left(c_{1}, c_{2}\right)$ control how far a particle will move in a single iteration. Typically these both are set to a value of 2 . The inertia weight (w) is used to control the convergence of behavior of pso. Small values of (w ) lead to more rapid convergence usually on suboptimal position, but large value may prevent divergence. In general the inertia weight is set according to the following equation:

$$
\mathrm{w}=\mathrm{w}_{\max }-\left(\frac{\left(\mathrm{w}_{\max }-\mathrm{w}_{\min }\right)}{\text { iter }_{\max }}\right) . \text { iter }
$$

updating position:

The i-particle position is updated by:

$$
X_{i d}^{k+1}=x_{i d}^{k}+v_{i d}^{k}
$$

For binary discrete search space, Kennedy and Ebhart [21] have adopted the pso to search in binary space by applying a sigmoid transformation to the velocity component given in (21) to squash the velocities into a range $[0,1]$,and force the component values of position to be 0 or 1 . The equation for updating positions in (20) then is replaced by (22)

$$
\begin{gathered}
\operatorname{sigmoid}\left(\mathrm{v}_{\mathrm{id}}^{\mathrm{k}}\right)=\frac{1}{1+\mathrm{e}^{-\mathrm{v}_{\mathrm{id}}^{\mathrm{k}}}} \\
x_{i d}^{k}=\left\{1 \text { if rand }<\operatorname{sigmoid}\left(v_{i d}^{k}\right),\right. \\
0 \text { other whise }\}
\end{gathered}
$$

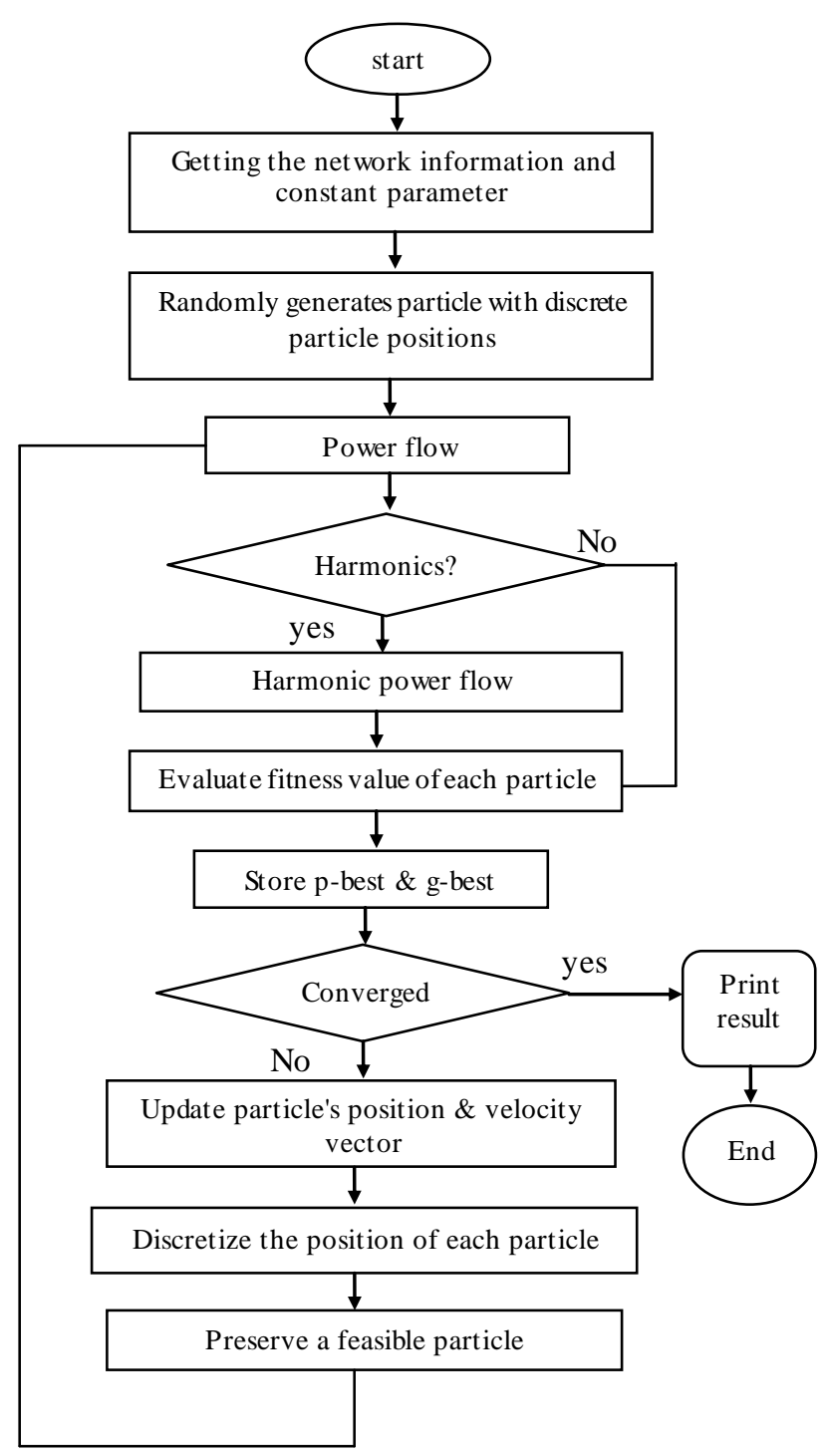

Fig. 1: flowchart of pso algorithm

\section{Simulation Results:}

The presented algorithm was implemented and coded in Matlab computing environment. In order to evaluate the proposed algorithm, the $12.6 \mathrm{kv}$ 33-bus IEEE distribution system is modified and applied, such that the objective function given in [16] is minimized. The single diagram of this system is shown in Fig.2. The specification of this system is given in [22] two nonelinear loads are replaced with loads in buses 5 and 26.This loads are two six-pulse converter with active and reactive power of $1 \mathrm{MW}$ and $0.75 \mathrm{MVAR}$.the harmonic current spectra of these converters is given in table 2 .

Fig.1 shows the flowchart of this algorithm 


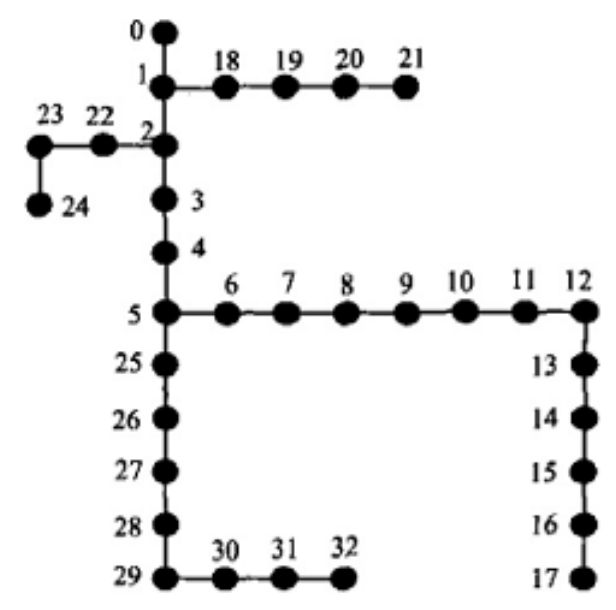

Fig. 2: single line diagram of 33-bus IEEE distribution system

Table 2: six-pulse converter harmonic spectra

\begin{tabular}{|c|c|}
\hline Harmonic order & Percentage of harmoniccurrent \\
\hline 1 & 100 \\
\hline 5 & 20 \\
\hline 7 & 14 \\
\hline 11 & 9 \\
\hline 13 & 8 \\
\hline 17 & 6 \\
\hline 19 & 5 \\
\hline 23 & 4 \\
\hline 25 & 4 \\
\hline
\end{tabular}

Capacitors and Distributed generations are commercially available in discrete sizes. In table 3 and 4 the size of capacitor bank and DG are given:

Table 3: capacitor sizes

\begin{tabular}{|c|c|c|}
\hline $\begin{array}{c}\text { Capacitor } \\
\text { size(kvar) }\end{array}$ & $\begin{array}{c}\text { Capacitor } \\
\text { size(kvar) }\end{array}$ & $\begin{array}{c}\text { Capacitor } \\
\text { size(kvar) }\end{array}$ \\
\hline 150 & 1500 & 2850 \\
\hline 300 & 1650 & 3000 \\
\hline 450 & 1800 & 3150 \\
\hline 600 & 1950 & 3300 \\
\hline 750 & 2100 & 3450 \\
\hline 900 & 2250 & 3600 \\
\hline 1050 & 2400 & 3750 \\
\hline 1200 & 2550 & 3900 \\
\hline 1350 & 2700 & 4050 \\
\hline
\end{tabular}

Table 4: DG sizes

\begin{tabular}{|c|c|c|c|c|c|}
\hline DG & 100 & 300 & 800 & 3000 & 5000 \\
\hline SIZES(KW) & & & & & \\
\hline
\end{tabular}

In table 5, rms voltages and THD of all buses for the base case (no installation) are demonstrated. As observed in table 5, the voltage level of some buses drop to level lower than acceptable limit and THD of some buses go to level higher than upper limit of defined range by IEEE-519 standard.

Table 5: bus voltage and THD before installation

\begin{tabular}{|c|c|c|c|c|c|}
\hline $\begin{array}{c}\text { Bus } \\
\text { number }\end{array}$ & $\mathbf{V}_{\text {rms }}$ & $\mathbf{T H D}_{\mathbf{v}}$ & $\begin{array}{c}\text { Bus } \\
\text { number }\end{array}$ & $\mathbf{V}_{\mathbf{r m s}}$ & $\mathbf{T H D}_{\mathbf{v}}$ \\
\hline 0 & 1 & - & 17 & 0.8693 & 7.83 \\
\hline 1 & 0.9952 & 0.23 & 18 & 0.9947 & 0.23 \\
\hline 2 & 0.9717 & 1.51 & 19 & 0.9911 & 0.23 \\
\hline 3 & 0.9573 & 2.50 & 20 & 0.9904 & 0.23 \\
\hline 4 & 0.9429 & 3.55 & 21 & 0.9897 & 0.23 \\
\hline 5 & 0.9077 & 7.50 & 22 & 0.9681 & 1.52 \\
\hline 6 & 0.9040 & 7.53 & 23 & 0.9613 & 1.53 \\
\hline 7 & 0.8989 & 7.57 & 24 & 0.9579 & 1.53 \\
\hline 8 & 0.8924 & 7.63 & 25 & 0.9040 & 7.82 \\
\hline 9 & 0.8863 & 7.68 & 26 & 0.8990 & 8.26 \\
\hline 10 & 0.8854 & 7.69 & 27 & 0.8869 & 8.38 \\
\hline 11 & 0.8838 & 7.70 & 28 & 0.8783 & 8.46 \\
\hline 12 & 0.8774 & 7.76 & 29 & 0.8745 & 8.50 \\
\hline 13 & 0.8750 & 7.78 & 30 & 0.8701 & 8.54 \\
\hline 14 & 0.8735 & 7.80 & 31 & 0.8692 & 8.55 \\
\hline 15 & 0.8721 & 7.81 & 32 & 0.8689 & 8.55 \\
\hline 16 & 0.8699 & 7.83 & & & \\
\hline
\end{tabular}

The DPSO algorithm is applied in this system for placement of capacitor and distributed generation for improving voltage profile and reducing loss and THD. In table 6 the locations and sizes of capacitors and Distributed generations are given. In table 7, rms voltages and THD of all buses after installation of capacitor and DG are demonstrated, as observed in table 7, after placement of capacitor and DG by this algorithm, no voltage and THD violation is observed in any buses. 
Optimal Place ment and Sizing of Capacitor and Distributed Generation with

TABLE 6: the locations of capacitors and DGs with proposed method

\begin{tabular}{|c|c|c|c|c|c|}
\hline Bus number & Capacitor(KVAR) & DG(KW) & Bus number & Capacitor(KVAR) & DG(KW) \\
\hline 0 & - & - & 17 & - & - \\
\hline 1 & 1350 & - & 18 & - & 5000 \\
\hline 2 & - & - & 19 & - & - \\
\hline 3 & 750 & - & 20 & 1050 & - \\
\hline 4 & - & - & 21 & - & - \\
\hline 5 & 1500 & 3000 & 22 & 900 & - \\
\hline 6 & 0 & - & 23 & - & - \\
\hline 7 & 0 & - & 24 & - & - \\
\hline 8 & 2700 & - & 25 & - & - \\
\hline 9 & - & 800 & 26 & - & - \\
\hline 10 & - & - & 27 & - & - \\
\hline 11 & - & - & 28 & - & - \\
\hline 12 & - & - & 29 & - & - \\
\hline 13 & - & - & 30 & 900 & - \\
\hline 14 & - & - & 31 & 1050 & - \\
\hline 15 & - & - & 32 & - & - \\
\hline 16 & - & - & & & \\
\hline
\end{tabular}

Table 7: bus voltage and THD after installation of capacitor and DG

\begin{tabular}{|c|c|c|c|c|c|}
\hline $\begin{array}{c}\text { Bus } \\
\text { number }\end{array}$ & $\mathbf{V}_{\mathbf{r m s}}$ & $\mathbf{T H D}_{\mathbf{v}}$ & $\begin{array}{c}\text { Bus } \\
\text { number }\end{array}$ & $\mathbf{V}_{\mathbf{r m s}}$ & $\mathbf{T H D}_{\mathbf{v}}$ \\
\hline 0 & 1 & - & 17 & 1.029 & 2.31 \\
\hline 1 & 1.003 & 0.08 & 18 & 1.009 & 0.08 \\
\hline 2 & 1.004 & 0.51 & 19 & 1.014 & 0.08 \\
\hline 3 & 1.008 & 0.83 & 20 & 1.016 & 0.08 \\
\hline 4 & 1.010 & 1.16 & 21 & 1.015 & 0.08 \\
\hline 5 & 1.022 & 2.33 & 22 & 1.003 & 0.51 \\
\hline 6 & 1.030 & 2.31 & 23 & 0.996 & 0.51 \\
\hline 7 & 1.033 & 2.31 & 24 & 0.993 & 0.52 \\
\hline 8 & 1.044 & 2.28 & 25 & 1.020 & 2.17 \\
\hline 9 & 1.044 & 2.28 & 26 & 1.017 & 1.96 \\
\hline 10 & 1.043 & 2.28 & 27 & 1.018 & 1.96 \\
\hline 11 & 1.042 & 2.29 & 28 & 1.018 & 1.96 \\
\hline 12 & 1.036 & 2.30 & 29 & 1.018 & 1.96 \\
\hline 13 & 1.034 & 2.30 & 30 & 1.026 & 1.94 \\
\hline 14 & 1.033 & 2.30 & 31 & 1.027 & 1.94 \\
\hline 15 & 1.032 & 2.31 & 32 & 1.027 & 1.94 \\
\hline 16 & 1.030 & 2.31 & & & \\
\hline & & & & & \\
\hline
\end{tabular}

In table 8 and Fig. 3 and 4 the results of two cases (before installation and after installation) are co mpared. As observed in table 8, after optimization by proposed method, power loss was decreased by $39.61 \%$ and maximu $\mathrm{m}$ THD was decreased by $72.74 \%$.
Table 8: comparison results

\begin{tabular}{|c|c|c|}
\hline RESULTS & $\begin{array}{c}\text { Before } \\
\text { installation }\end{array}$ & Afterinstallation \\
\hline $\mathrm{P}_{\text {loss }}(\mathrm{kw})$ & 578 & 349 \\
\hline $\mathrm{THD}_{\max }(\%)$ & 8.55 & 2.33 \\
\hline $\mathrm{V}_{\max }(\mathrm{pu})$ & 1 & 1.04 \\
\hline $\mathrm{V}_{\min }(\mathrm{pu})$ & 0.86 & 0.99 \\
\hline
\end{tabular}

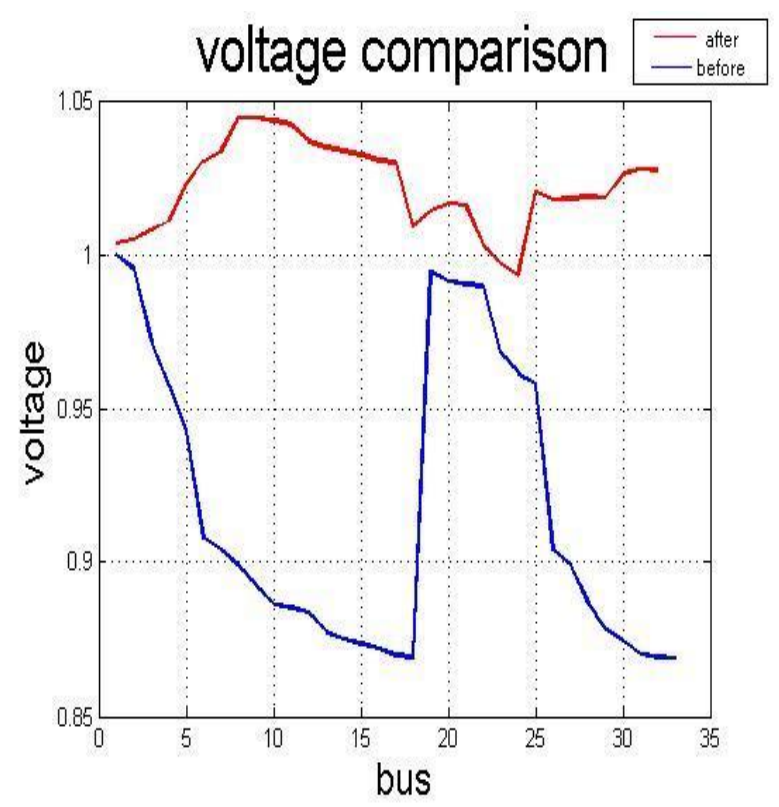

Fig. 3: voltage comparison 


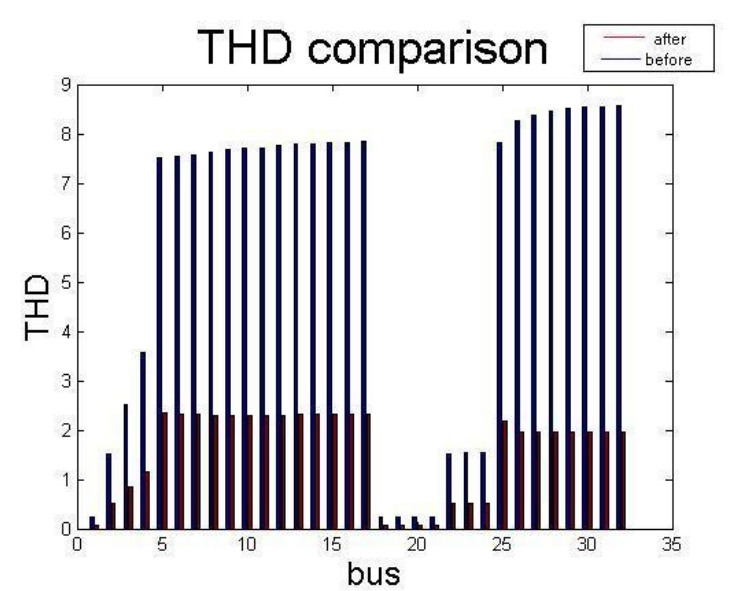

Fig. 4: THD comparison

\section{Conclusion:}

In this paper a modified version of pso algorithm (DPSO) which is suitable for discrete problems is applied for optimal placing and sizing of capacitor and DG in distribution system. In some works in spite of taking harmonic into account like [17] resonance occurs at some frequencies, in this work inclusion of resonance index in the objective function prevents occurring resonance. Simulation was done on the modified 33-bus IEEE test system and results are printed. The results show a significant reduction of power losses and THD and improvement of voltage profile in the system after optimal placement and sizing of capacitor and DG by proposed method.

\section{References}

[1] M.Wang,J.Zhong," a novel method for distributed generation and capacitor optimal placement considering voltage profile",IEEE,2011.

[2] K.Hghdar,H.A.Shayanfar," optimal placement and sizing of DG and capacitor for the loss reduction via methods of generalized pattern search and genetic algorithm",IEEE.2010.

[3] A.Mady,I.Tawfeek,"optimal sizing of capacitor banks and distributed generation in distorted distribution networks by genetic algorith ms",CIRED, $20^{\text {th }}$ international conference on electricity distribution, 2009.

[4] K. Nara, Y. Hayashi, K. Ikeda, T. Ashizawa," Application of tabu search to optimal placement of distributed generators", IEEE PES Winter Meeting, vol. 2, 2001, pp. 918-923.

[5] H.L. Willis," Analytical methods and rules of thumb for modeling DG distribution interaction",IEEE PES Summer Meeting, vol. 3, Seattle,WA, Jul 2000.
[6] N. Acharya, P. Mahat, N. Mithulananthan, "An analytical approach for DG allocation in primary distribution network, Int. J. Electr. Power Energy Syst. 2006, PP.669-678.

[7] K.H. Kim, Y.J. Lee, S.B. Rhee, S.K. Lee, S.-K. You, "Dispersed generator placement using fuzzy GA in distribution systems", in: IEEE PES Summer Meeting, vol. 3 July, 2002, pp. 11481153.

[8] Y.A. Katsigiannis, P.S. Georgilakis," Optimal sizing of small isolated hybrid power systems using tabu search", Journal of Optoelectronics and Advanced Materials 10 (5) (2008) 1241-1245.

[9] J.O. Kim, S.W. Nam, S.K. Park, C. Singh, "Dispersed generation planning using improved Hereford Ranch algorithm", Electr. Power Syst. 1998.

[10] J. Kennedy, R. Eberhart, "Particle swarm optimization", IEEE . Conf. Neural Networks, Perth, Australia, November 1995, pp. 1942-1948.

[11] K.E. Parsopoulos, M.N. Vrahatis," On the computation of all minimizers through particle swarm optimization, IEEE Trans. Evolut. Comput,2004,PP.211-224.

[12] X. Yu, X. Xiong, Y. Wu," A PSO-based approach to optimal capacitor placement with harmonic distortion consideration", Electr. Power Syst. 2004,227-233.

[13] R.A. Krohling, L.S. Coelho," Co-evolutionary particle swarm optimization using Gaussian distribution for solving constrained optimization problems" IEEE Trans. Syst,2006,PP. 1407-1416.

[14] U. Baumgartner, C. Magele, W. Renhart, "Pareto optimality and particle swarm optimization", IEEE Trans. 2004,PP.1172-1175.

[15] "Modeling and Simulation of the Propagation of Harmonics in Electric Power Network Part I: Concepts, Models and Simulation Techniques," Task Force on Harmonics Modeling and Simu lation, IEEE Trans. on PWRD, Vol. 11, No. 1, Jan. 1996 pp. 452-465.

[16] "Modeling and Simulation of the Propagation of Harmonics in Electric Power Network Part II: Sample Systems and Examples Task Force on Harmonics Modeling and Simu lation", IEEE Trans on Power Delivery, Vol. 11, No. 1, pp. 466-474, Jan. 1996.

[17] S.A.taher,S.A.Hosseni,"a novel technique for optimal capacitor placement and sizing in distribution systems with non-linear loads based on harmonic source identification",IUST,2008,pp.99106.

[18] D. Singh, D., K.S. Verma, "Multiobjective optimization for DG planning with loadmodels", 
IEEE Transactions on Power Systems 2009,pp. 427-436.

[19] L.F. Ochoa, A. Padilha-Feltrin, G.P. Harrison, "Evaluating distributed generation impacts with a multiobjective index", IEEE Transactions on Power Delivery 2006,pp.1452-1458.

[20] J. Kennedy and R. C. Eberhart, "A Discrete Binary Version of the Particle Swarm Algorithm Proc. of the conference on Systems, Man,1997, pp.4104-4109.

[21] S.K. Goswami, S.K. Basu, A new algorith m for the reconfiguration of distribution feeders for loss minimization, IEEE Trans,1992,1484-1491.

[22] Abou-Ghazala,A.,"optimal capacitor placement in Distribution Systems Feeding non linear loads", IEEE Bolgona Power Teach conference,2003..

\section{Authors' Profiles}

Mohamadreze Heydari born in sari,mazandaran,Iran in 1985.recieved B.S degree from babol university of technology in 2010. is a graduate student of babol university of technology

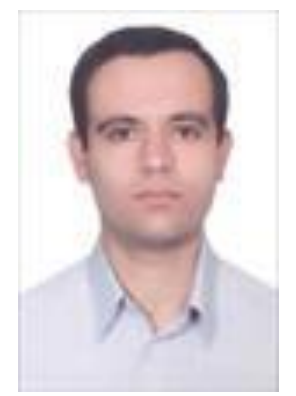

Seyed Mehdi Hosseini received B.S degree from university of mazandaran in 2000,and received M.S degree from Iran university of science and technology in 2002,recieved $\mathrm{PhD}$ degree from Iran university of science and technology in 2009, faculty member of babol university of technology, babol, Iran. His research interests are Reliability of Distribution Systems, Distributed Generation, FACTS Devices

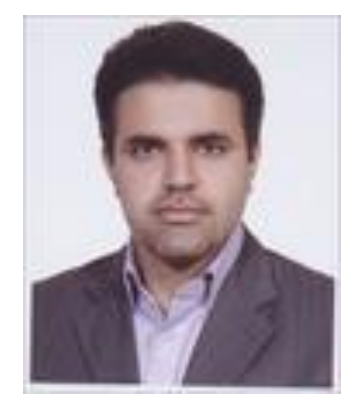

Seyed Asghar Gholamian received B.S degree from khaje nasiredin toosi university of technology in 1999, and received M.S degree university of mazandaran in 2001,recieved $\mathrm{PhD}$ degree from khaje nasiredin toosi university of technology 2009 ,faculty member of babol university of technology, babol, Iran. His research interests are:

Design, simulation, modeling and control of electrical machines

$>$ Condition monitoring and fault diagnosis of electric machinery

$>$ Electric and Hybrid Electric Vehicles motor
$>$ Power converters for electric machines

Simulation techniques such as finite elements analys is and MATLAB

$>$ Novel electric machines for different applications

Renewable Energy

How to cite this paper: M. Heydari, S.M. Hosseini, S.A. Gholamian,"Optimal Placement and Sizing of Capacitor and Distributed Generation with Harmonic and Resonance Considerations Using Discrete Particle Swarm Optimization", International Journal of Intelligent Systems and Applications(IJISA), vol.5, no.7, pp.42-49, 2013. DOI: 10.5815/ijisa.2013.07.06 